\title{
The Risks of miRNA Therapeutics: In a Drug Target Perspective
}

This article was published in the following Dove Press journal:

Drug Design, Development and Therapy

\author{
Song Zhang ${ }^{1,2}$ \\ Zhujun Cheng ${ }^{3}$ \\ Yanan Wang' \\ Tianyu Han' \\ 'Jiangxi Institute of Respiratory Disease, \\ The First Affiliated Hospital of Nanchang \\ University, Nanchang, 330006, People's \\ Republic of China; ${ }^{2}$ College of \\ Pharmaceutical Sciences, Zhejiang \\ University, Hangzhou, 310058, People's \\ Republic of China; ${ }^{3}$ Department of Burn, \\ The First Affiliated Hospital of Nanchang \\ University, Nanchang, 330006, People's \\ Republic of China
}

\begin{abstract}
RNAi therapeutics have been growing. Patisiran and givosiran, two siRNA-based drugs, were approved by the Food and Drug Administration in 2018 and 2019, respectively. However, there is rare news on the advance of miRNA drugs (another therapeutic similar to siRNA drug). Here we report the existing obstacles of miRNA therapeutics by analyses for resources available in a drug target perspective, despite being appreciated when it began. Only 10 obtainable miRNA drugs have been in clinical trials with none undergoing phase III, while over 60 siRNA drugs are in complete clinical trial progression including two approvals. We mechanically compared the two types of drug and found that their major distinction lay in the huge discrepancy of the target number of two RNA molecules, which was caused by different complementary ratios. One miRNA generally targets tens and even hundreds of genes. We named it "too many targets for miRNA effect" (TMTME). Further, two adverse events from the discontinuation of two miRNA therapeutics were exactly answered by TMTME. In summary, TMTME is inevitable because of the special complementary approach between miRNA and its target. It means that miRNA therapeutics would trigger a series of unknown and unpreventable consequences, which makes it a considerable alternative for application.
\end{abstract}

Keywords: RNAi, miRNA, siRNA, therapeutics

\section{Introduction}

In 1993, Lee et al discovered endogenous single-stranded approximately 22-nt lin-4 (a miRNA) could decrease the level of LIN-14 protein in C. elegans, ${ }^{1}$ and since then, researchers have reported a series of miRNAs that could inhibit the expression of specific proteins. In 2001, Elbashir et al reported double-stranded 21-nucleotide (nt) siRNA could induce RNA interference (RNAi) in different mammalian cell lines, ${ }^{2}$ and soon siRNAs were used as useful tools for gene silencing in biomedical research. Both types of RNA molecules could lead to inhibition of gene expression, but miRNA is complementary to the $3^{\prime}$ untranslated region of $\mathrm{mRNA}^{1}$ and siRNA is complementary to the coding region of mRNA. ${ }^{2}$ However, two similar mechanistic RNA molecules were under different progression for biomedical applications. In 2006, Craig Mello and Andrew Fire were awarded the Nobel Prize in Physiology or Medicine for their contributions to RNAi, which, however, excluded work on miRNA. Until 2020, a number of treatments based on siRNA technology have undergone clinical trials, and two such products, patisiran ${ }^{3}$ and givosiran ${ }^{4}$, have been approved. But nearly 30 years later, miRNA did not benefit treatment of diseases even with none entering phase III clinical trials. In this article, we explore
Correspondence: Tianyu Han Email hantianyu87@I63.com 
the delayed development of miRNA in a drug target perspective, and identify therapeutic risks of miRNA despite its great appreciation by many reports. ${ }^{5-9}$

\section{Comparison of miRNA Drugs and siRNA Drugs}

To understand the latest and detailed progression of RNAi, we first obtained clinical trial information of miRNA drug and siRNA drug (including shRNA, a small RNA molecule executing the same function as siRNA) from ClinicalTrials. gov, ${ }^{10}$ Drugs@FDA database, ${ }^{11}$ a series of literature, ${ }^{3,4,12,13}$ and a company report ${ }^{14}$ (Tables 1 and 2). The information presented in Table 2 originated from Weng's study ${ }^{13}$, and we updated the current phase status of the clinical trials for these drugs. In our statistics, it launched 10 miRNA drugs in clinical trial, with one phase I, four phase II and five terminated/suspended (Table 1 and Figure 1A). However, 57 siRNA drugs (targeting human proteins/genes) were ongoing or completed clinical trials, including 16 phase I, 16 phase II, eight phase III, 23 terminated/suspended therapeutics (Table 2 and Figure 1A). As shown (Figure 1B), no miRNA drugs were in phase III trials, while siRNA drugs seemed to be in a complete clinical trial system without missing any segments. Moreover, we found that miRNA drugs suffered $50 \%$ terminated/suspended therapeutics, while $35.38 \%$ terminated/suspended therapeutics appeared in siRNA drugs (Figure 1B). Therefore, it may indicate there were potentially unclear obstacles for miRNA therapeutics.

Inherently, miRNA is endogenously produced and siRNA is exogenously designed. Designers can exactly endow siRNA giving them the purpose of gene silencing, while endogenous miRNA seemed more complicated because nobody assigned them specific tasks. We mechanically analyzed the differences between miRNA and siRNA in their complementary modes with the target sequences. As expected, Figure 2A showed a flexible complementary ratio of miRNA with target sequence (within the range 20-90\%) and none with complete complementation, but all siRNAs had $100 \%$ complementary ratio. The less restricted complementary mode may lead to low specificity of target sequence. Next, we employed miRTarBase ${ }^{15}$ to obtain targets of miRNAs for ten miRNA drugs, and compared the number of targets in miRNA drug* (referring to all targets of miRNA including experiment-validated and high-throughput results in miRTarBase), miRNA drug (referring to targets of miRNA only including experiment-validated results) and siRNA drugs. Beyond our expectation, the targets of the miRNA drug ranged from 30 to 250 in number and almost all miRNA drug* were over 500 and even 1000, but the si0052NA drug generally targets 1-3 genes (Figure 2B). The majority of miRNA targets tens and hundreds of genes, and we named it "too many targets for miRNA effect" (TMTME).

Table I Clinical Information of miRNA Drugs

\begin{tabular}{|c|c|c|c|c|}
\hline Drug Name & $\begin{array}{l}\text { Target(s)/Employed } \\
\text { miRNA(s) }\end{array}$ & $\begin{array}{l}\text { Current } \\
\text { Status }\end{array}$ & Condition(s) & Company \\
\hline $\begin{array}{l}\text { Lademirsen } \\
\text { (SAR339375, RG-012) }\end{array}$ & miR-2I & II & Alport syndrome & Genzyme \\
\hline MRG-20I (Remlarsen) & miR-29 & II & Keloid & miRagen Therapeutics, Inc. \\
\hline RG-I25 (AZD4076) & miR-103/I07 & II & Nonalcoholic fatty liver disease & AstraZeneca \\
\hline MRG-I06 & miR-I55 & 1 & Lymphomas; leukemias & miRagen Therapeutics, Inc. \\
\hline MRG-IIO & miR-92a & 1 & Skin excisional wound & miRagen Therapeutics, Inc. \\
\hline MesomiR I & miR-16 & Suspended & $\begin{array}{l}\text { Malignant pleural mesothelioma; non-small } \\
\text {-cell lung cancer }\end{array}$ & $\begin{array}{l}\text { Asbestos Diseases Research } \\
\text { Foundation }\end{array}$ \\
\hline Miravirsen & miR-I 22 & Suspended & Chronic hepatitis C & Santaris Pharma A/S \\
\hline RG-I0I & $\operatorname{miR}-122$ & Discontinued & Chronic hepatitis C & Regulus Therapeutics Inc. \\
\hline $\begin{array}{l}\text { pSil-miR200c and PMIS } \\
\text { miR200a }\end{array}$ & $\mathrm{miR}-200 \mathrm{a} / \mathrm{c}$ & Discontinued & Tooth extraction status nos & University of lowa \\
\hline $\mathrm{MR} \times 34$ & miR-34a & Discontinued & $\begin{array}{l}\text { Melanoma; primary liver cancer; } \\
\text { hematologic malignancies }\end{array}$ & Mirna Therapeutics, Inc. \\
\hline
\end{tabular}




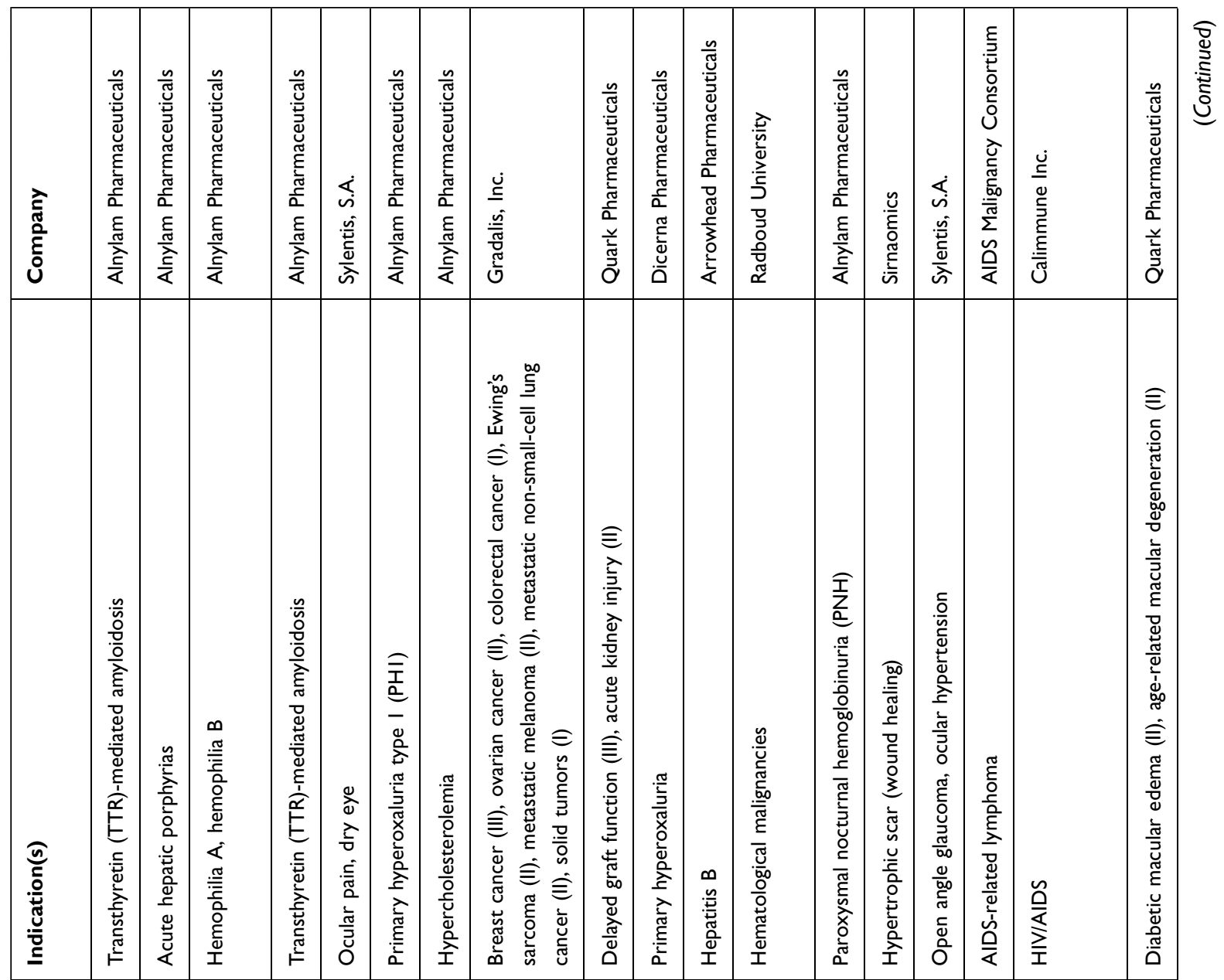

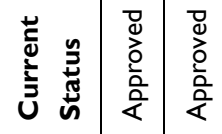

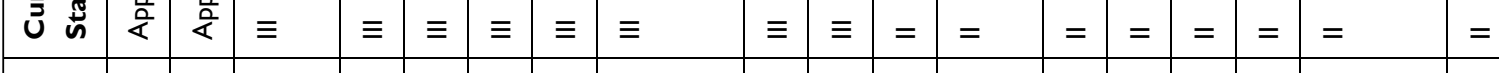

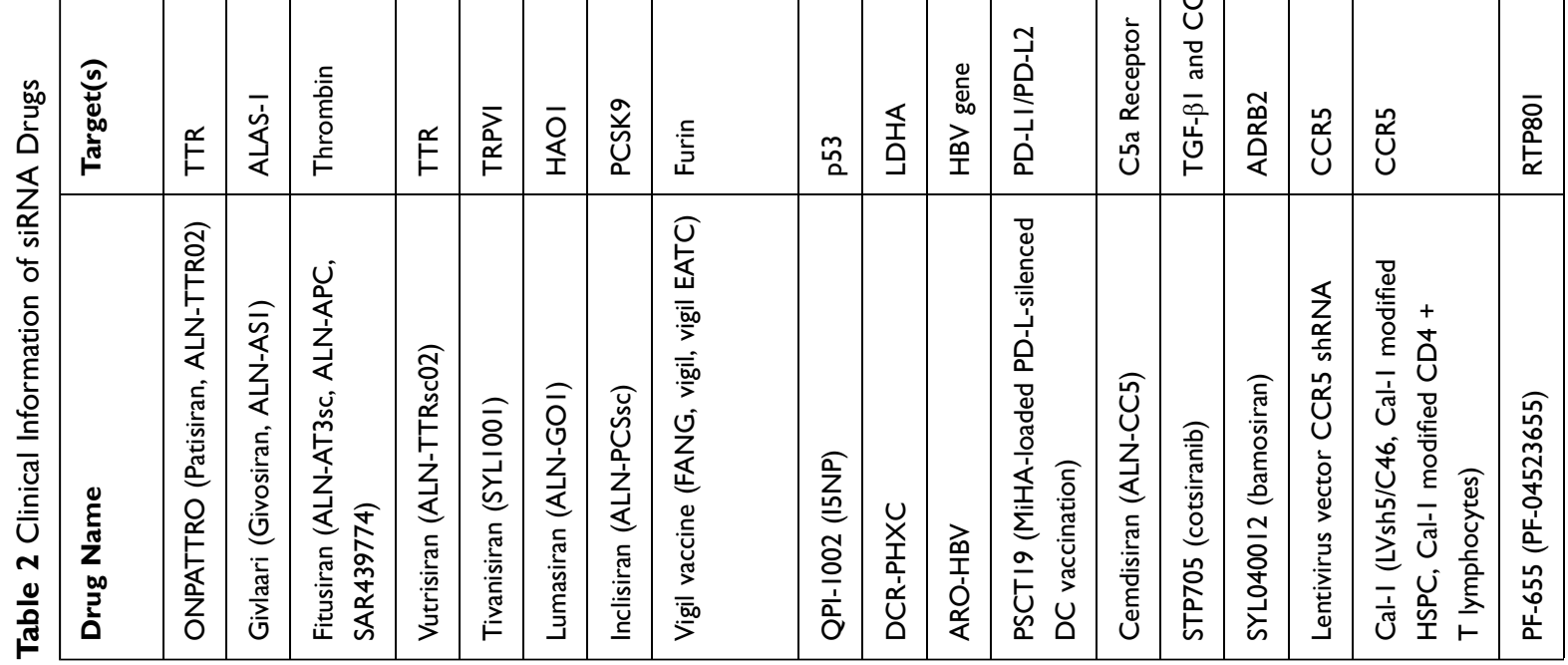




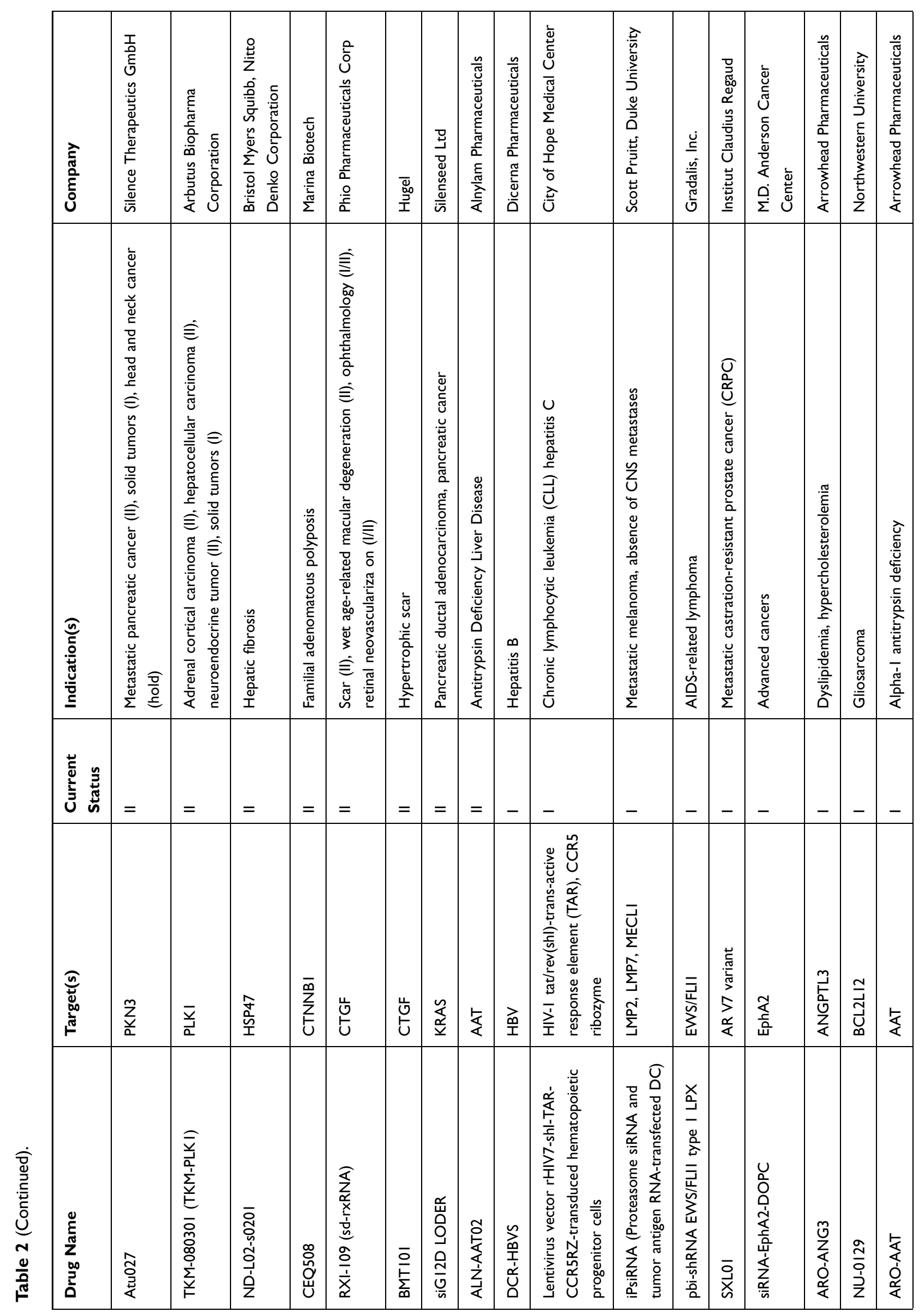




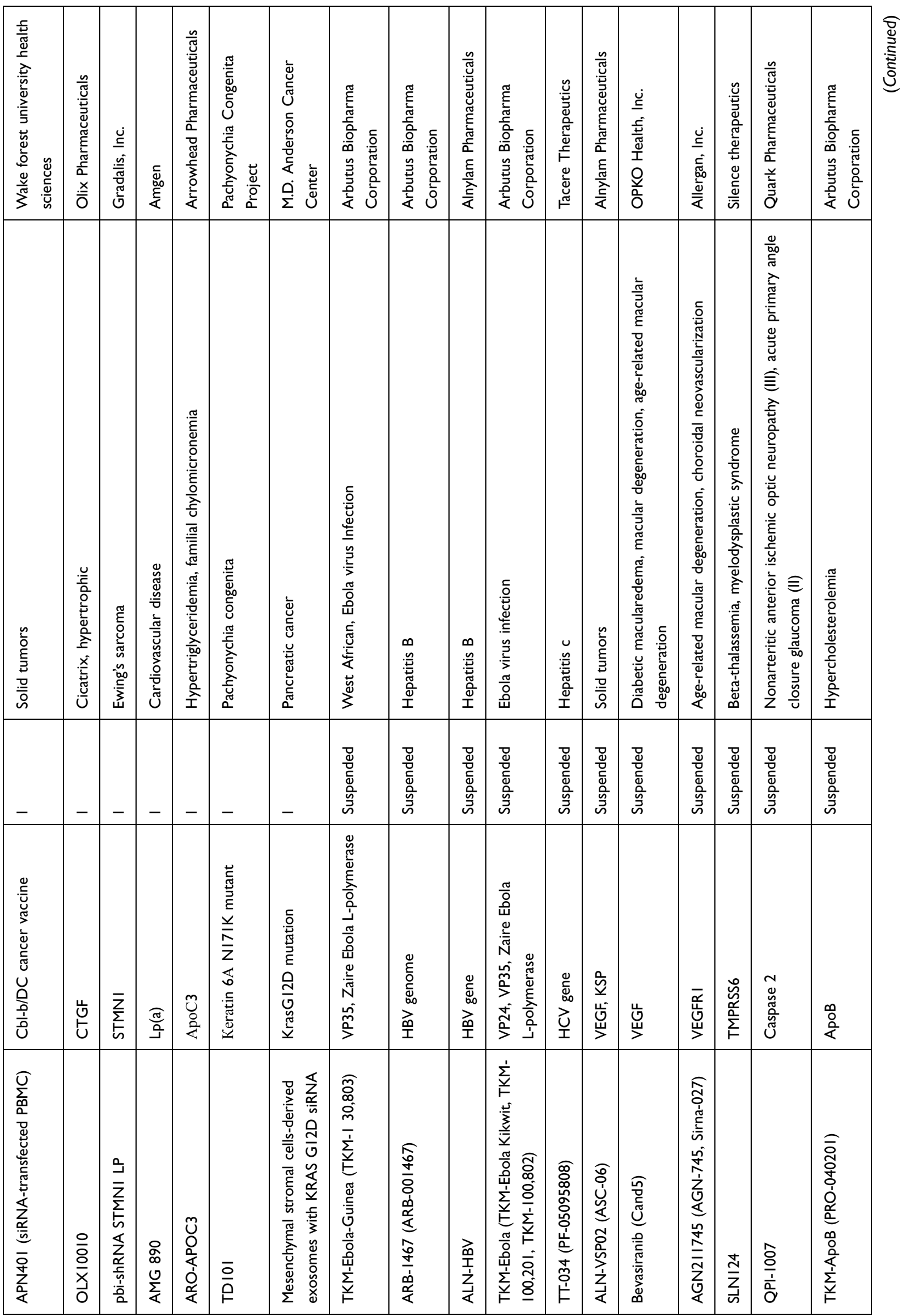




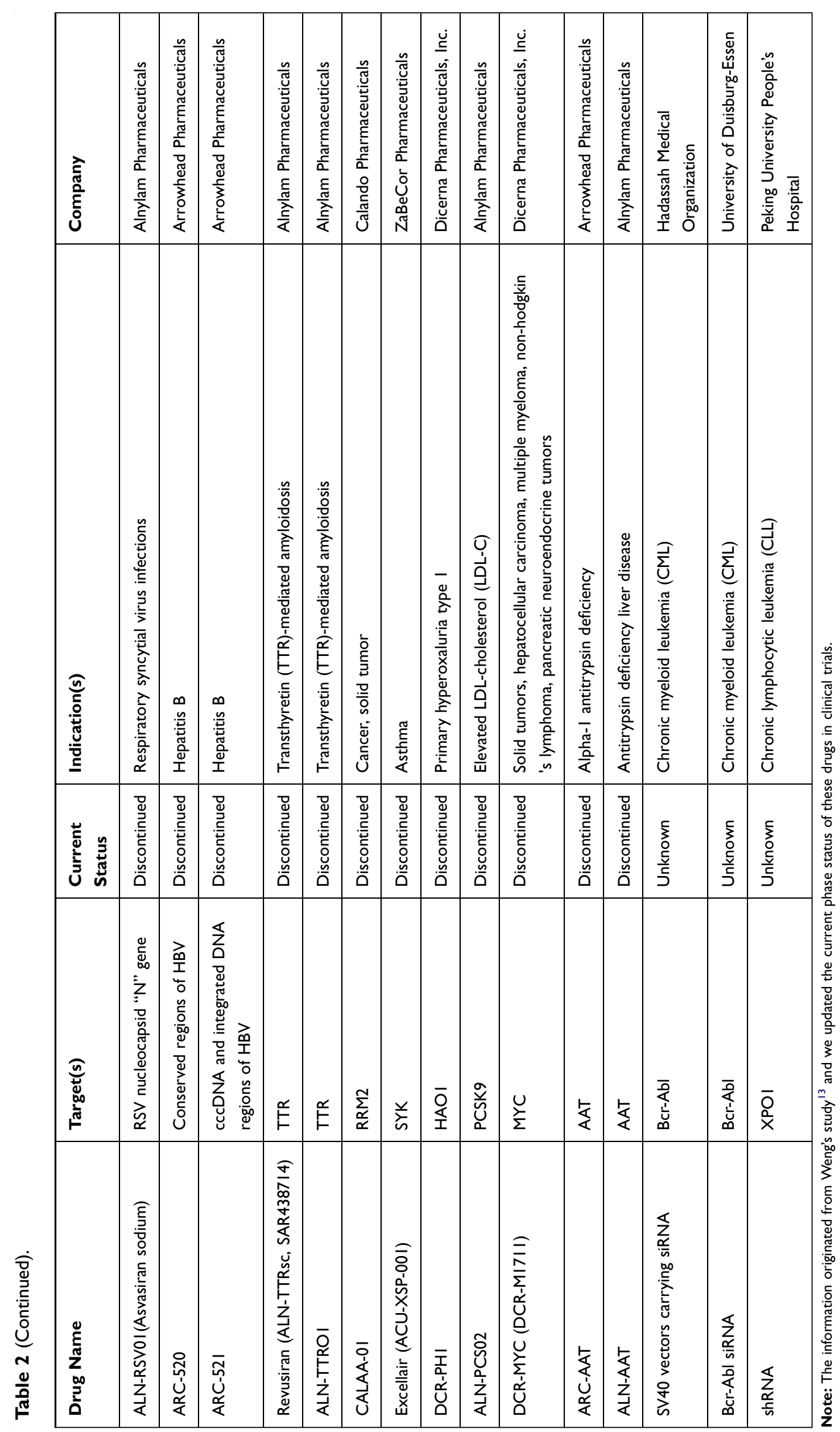


A

25

15

0

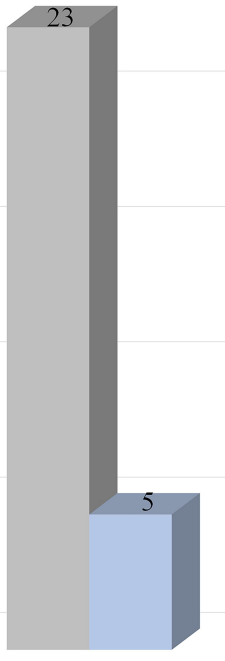

Terminated/Suspended
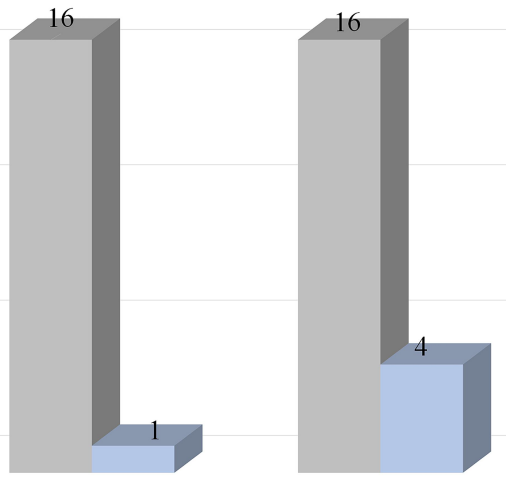

Phase I

Phase II

$\square$ siRNA Drug $\square$ miRNA Drug

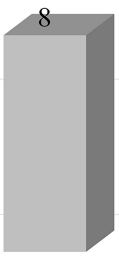

Phase III

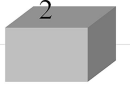

Approved

B

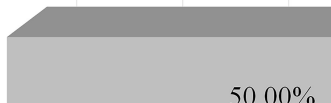

$10.00 \%$

$40.00 \%$

siRNA Drug

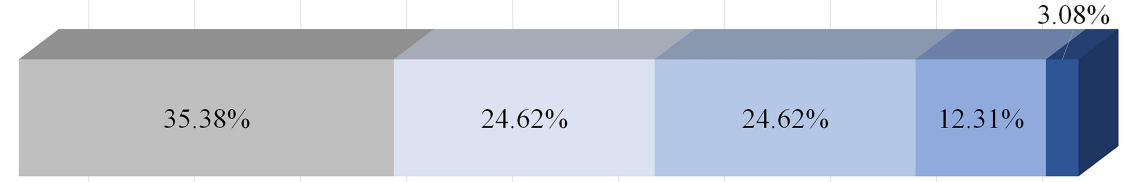

$\varpi$ Terminated/Suspended $\square$ Phase I $\square$ Phase II $\square$ Phase III $\square$ Approved

Figure I Clinical progression of miRNA drug and siRNA drug. (A) The number of miRNA drugs and siRNA drugs in different clinical periods (terminated/suspended, phase I, phase II, phase III, approved). (B) The ratio of miRNA drugs and siRNA drugs of different clinical periods.

To further explore the cause for the delayed development of current miRNA therapeutics compared to siRNA drugs, we attempted to examine how many targets were not approved when these miRNA drugs entered into the tested subjects. Therefore, we collected all FDA-approved drugs (targeting human genes/proteins) from 1939 to 2019..$^{3,4,16-19}$ Figure 3A showed all ten miRNA drugs had tens and hundreds of unapproved targets, far beyond the siRNA drug. So, how many targets does a recognized drug have? We next profiled the target number of approved drugs (Figure 3B), and found the number of drug targets was no more than five. SiRNA drugs fell within the range, but miRNA drugs did not.

\section{Analyses for Two Discontinued miRNA Therapeutics-based Projects}

To further verify this finding, we collected and analyzed two available miRNA clinical projects that suffered 
A

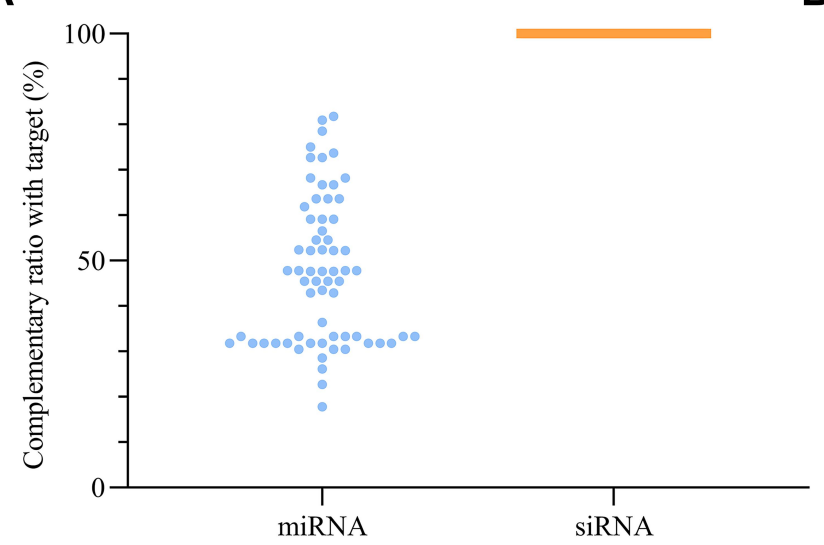

B

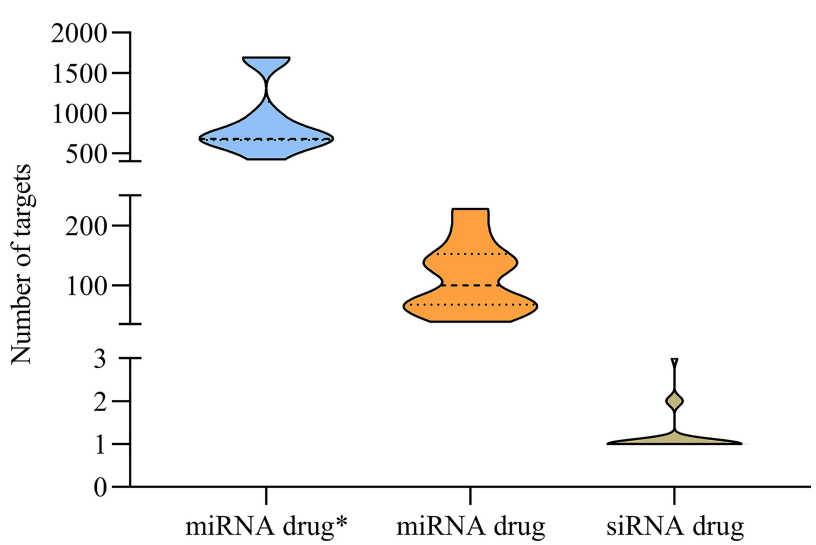

Figure 2 Flexible complementary ratio between miRNA with target sequence led to TMTME. (A) Complementary ratios of miRNA and siRNA with target. (B) Target number of miRNA drug* (all containing high-throughput results), miRNA drug (validated) and siRNA drug.

A

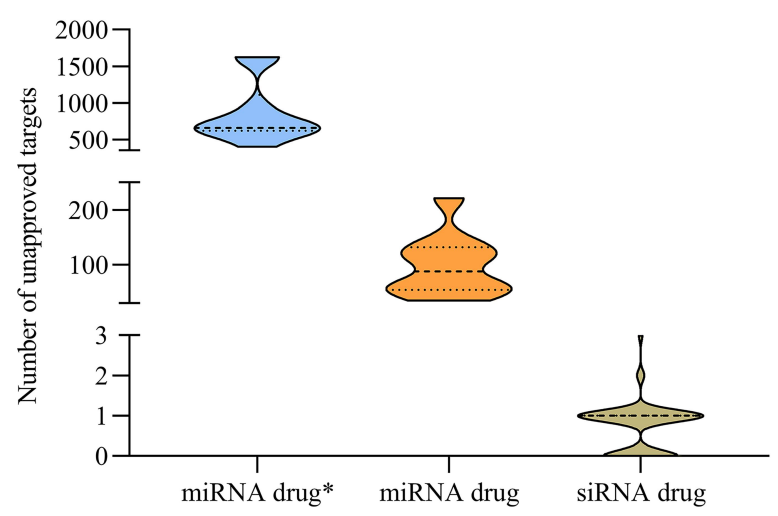

B

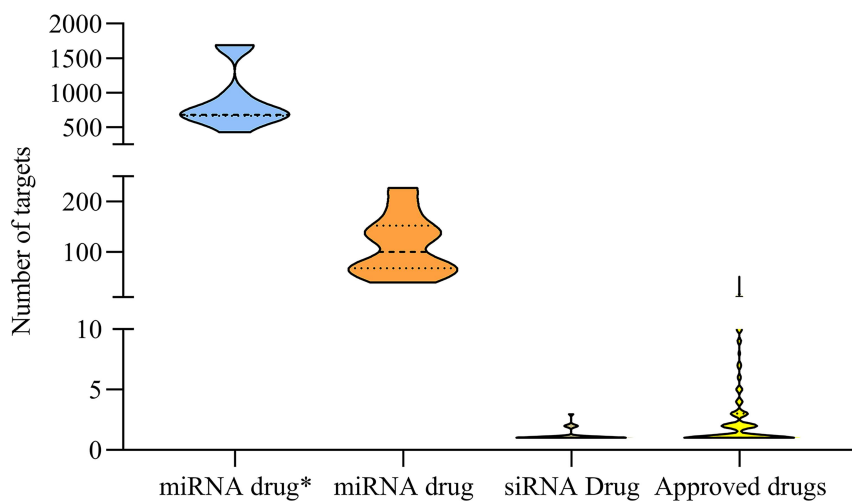

Figure 3 Target number of siRNA drugs obeyed the regular of all approved drug target number. (A) Unapproved targets of miRNA drug*, miRNA drug and siRNA drug. (B) Target number of miRNA drug*, miRNA drug, siRNA drug and approved drugs.

discontinuation caused by adverse events. According to the ClinialTrials.gov database ${ }^{10}$ (NCT01829971) recorded, MRX34 (a miR-34a mimic) in a phase I clinical trial led to tested objects undergoing five serious immune-related adverse events, therefore terminating the project. Using KOBAS (a web server for annotation and identification of enriched pathways and diseases), ${ }^{20}$ we enriched 139 experiment-validated target genes of miR-34a in pathway analysis, and selected the top ten pathways, see Figure 4A according to the ranking of enrichment score and Figure $4 \mathrm{~B}$ according to the ranking of number of genes. It showed that two immune-related pathways (cytokine signaling in the immune system and immune system) were on the list, and some related pathways like signaling by interleukins were also included. We further found that there were 15 approved genes and 25 unapproved genes in the immune system pathway and 13 approved genes and 16 unapproved genes in cytokine signaling in the immune system pathway (Figure 4C). Based on these facts, it is not hard to understand the emergence of five serious immune-related adverse events in phase I. According to the literature ${ }^{12}$ and the Regulus Therapeutics Inc. company report, ${ }^{14}$ RG-101, an anti-miR-122 drug, succeeded in phase I but was discontinued in phase II for the occurrence of a few cases of hyperbilirubinemia. We next enriched 71 experimentvalidated target genes of miR-122 in disease analysis by KOBAS web server. However, no hyperbilirubinemiarelated diseases were among the listed top 10 (Figure 4D and E). And hepatocellular carcinoma (HCC) was enriched as it has been reported that miR-122, a most frequent miRNA in the adult liver, ${ }^{21}$ played a crucial role in HCC in a series of literature, ${ }^{6,22,23}$ indicating the correctness of 
A

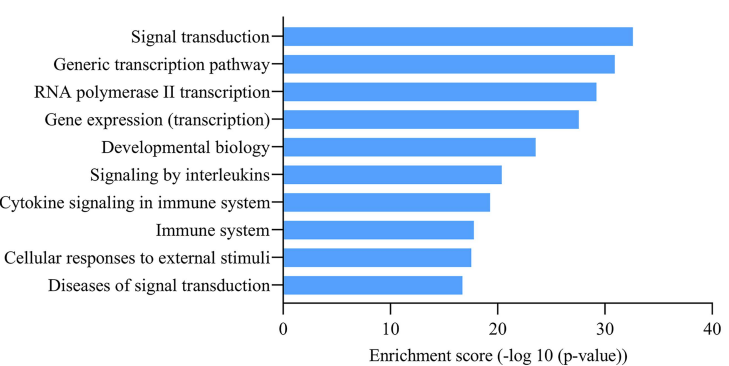

C

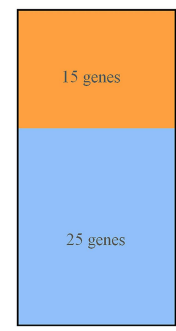

Immune system

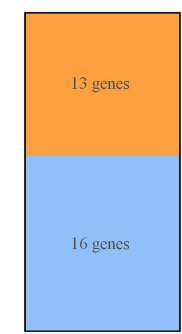

Cytokine signaling in immune system

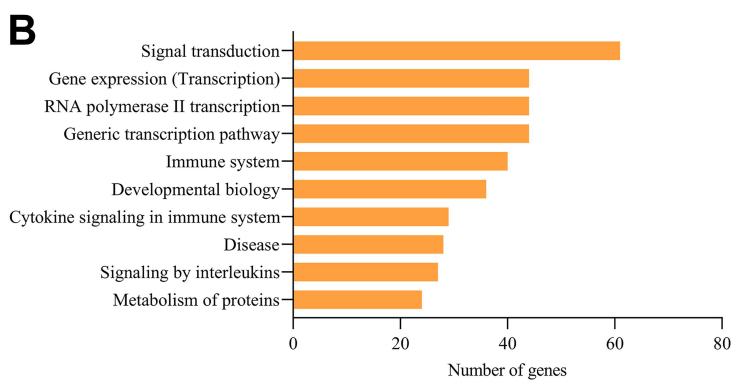

D

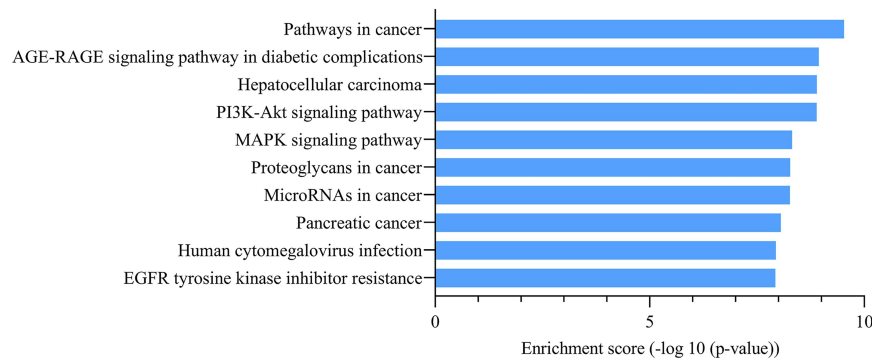

E

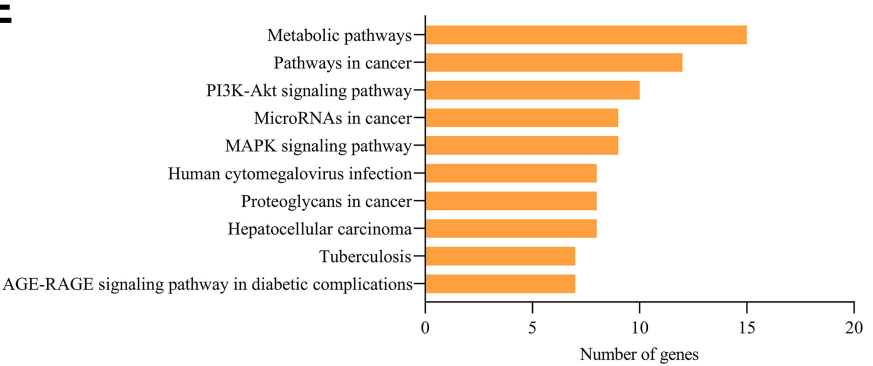

Figure 4 Analyses of discontinuation of two miRNA-based clinical projects. (A and B) Enrichment for targets of MRX34 in terms of enrichment score and number of genes. (C) Unapproved and approved targets number of MRX34 validated targets in the immune system and cytokine signaling in the immune system. (D and E) Enrichment for targets of miR-I22 (drug RG-I0I) in terms of enrichment score and number of genes.

the enrichment. Given its emergence in phase II not in phase I, we filtrated 71 target genes in the literature and the KEGG database, ${ }^{24}$ and got seven hyperbilirubinemia or jaundice (hyperbilirubinemia-related disease) related genes (Figure 5). Only seven related genes were found, and it revealed why hyperbilirubinemia did not occur in most tested objects in phase I but appeared in a few cases in phase II.

\section{Future Directions and Conclusions}

TMTME is a typical and inevitable property of miRNA molecules, which is caused by incomplete complementation with the target sequence. TMTME leads to that miRNA could bind to various sequences suitable for the interaction (including protein-coding genes, $\operatorname{lncRNA},{ }^{25}$ circRNA, ${ }^{26}$ etc), which is different from all approved drugs (including siRNA drugs) with only a few targets. Emerging siRNA-based products, patisiran and givosiran approved by the FDA, have been in clinical application, however, miRNA therapeutics was still in its early clinical stage. Therefore, both introduction and removal of miRNA in humans can lead to changes of a wide series of pathways and some of them are unknown, even unpredictable, probably triggering disorders of physiological function or the occurrence of additional disease.

Targeted drug delivery is a pattern of delivering drugs to specific lesion sites of a patient, largely based on nanomedicine, which can enhance solubility and efficacy of drugs and avoid needless interaction with healthy tissues. $^{27,28}$ Targeted drug delivery systems can be designed by recognition of a specific feature in lesion sites. ${ }^{29}$ In cancers, the antigens and receptors on cell membranes are considered suitable targets of recognition sites for design of these nanoparticles. ${ }^{29}$ Therefore, targeted drug delivery systems may eliminate or weaken the existing obstacles that were caused by TMTME. 


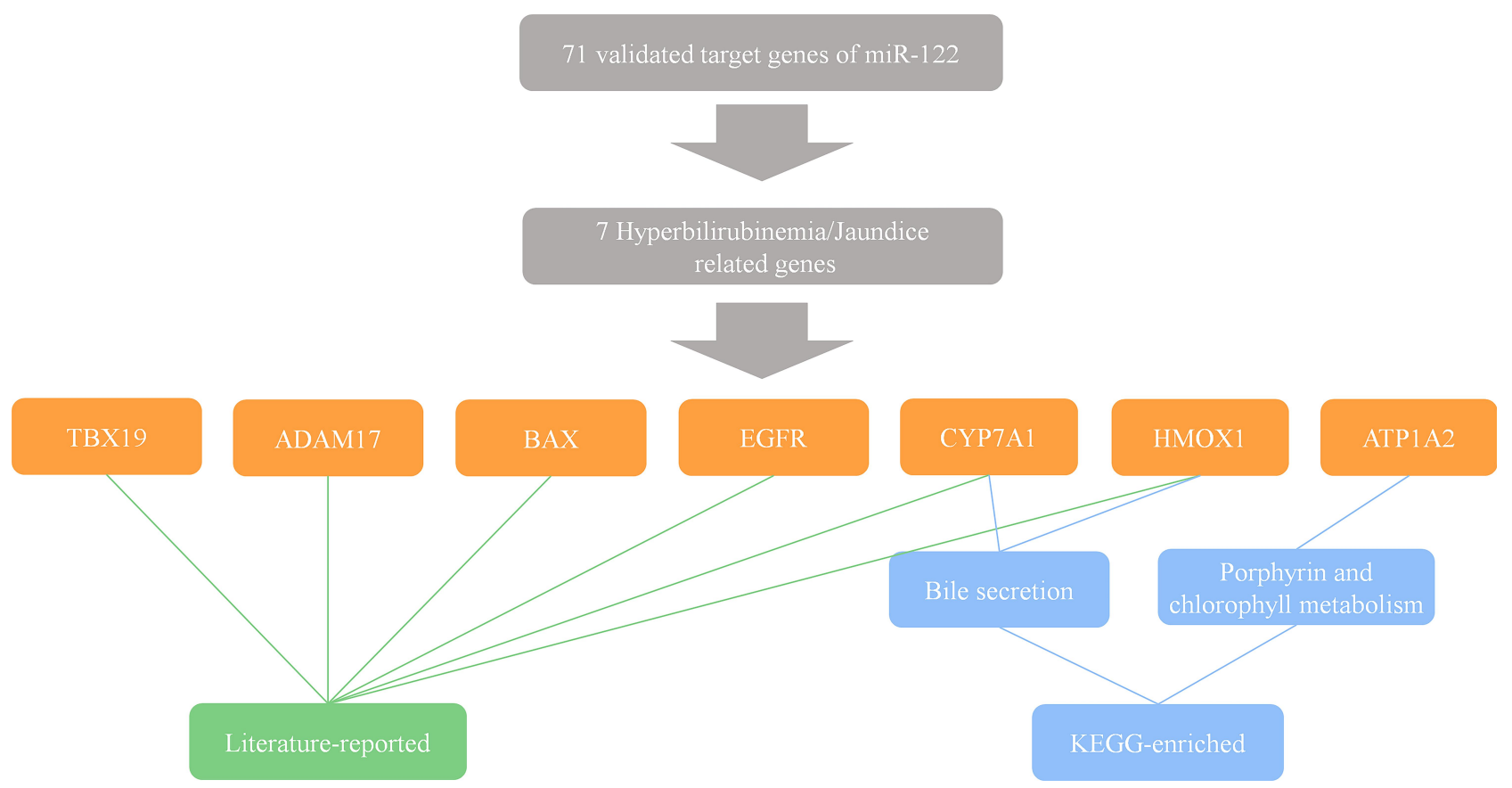

Figure 5 Discontinuation of RG-I0I is caused by its hyperbilirubinemia or jaundice-related targets. The hyperbilirubinemia or jaundice-related target genes of miR-I22 are identified by literature searching and KEGG enrichment.

Delivering miRNA drugs to pathogenic sites may efficiently avoid excessive toxicity and side effects. However, the defects of the system are high cost, hard to make productivity for delivering nucleotides, and the increased difficulty for adjusting the dosages. ${ }^{28,30}$ Moreover, due to instability of unprotected miRNAs, delivering miRNAs required chemical modifications to avoid rapid degradation in serum, which may impair specificity of miRNAs and lead to off-target effects. ${ }^{31}$ Besides, parenteral or local injection is the primary approach for delivering miRNA drugs, ${ }^{32}$ which reduces the amount of miRNA that is transported to the target tissue. Another challenge is that exogenous artificial miRNAs will trigger competition and saturation effect, a competition among exogenous and the endogenous miRNAs for the intracellular machinery, and thus affecting unexpected gene expression and leading to untoward side effects. ${ }^{33-35}$

Conclusively, in this study, we analyzed the key cause that leads to the slow development of miRNA therapeutics in a drug target perspective and attributed it to TMTME.

\section{Resources, Databases and Servers}

We use ClinicalTrials.gov database ${ }^{10}$ for obtaining available information of clinical trials, a series of literature ${ }^{36-89}$ for obtaining information for complementary ratio of miRNA with target gene, a study ${ }^{90}$ for getting all siRNA sequences with target genes, NCBI gene and NCBI blast database for calculating complementary ratio of siRNA with mRNA, $\mathrm{KOBAS}^{20}$ web server for enriching pathways and diseases for adverse events' condition of miRNA therapeutics, KEGG database ${ }^{24}$ for obtaining hyperbilirubinemia or jaundice-related genes and pathways.

\section{Acknowledgments}

This work is supported by the National Natural Science Foundation of China (81902346) and Natural Science Foundation of Jiangxi Province (20192BAB215038).

\section{Disclosure}

The authors report no conflicts of interest in this work.

\section{References}

1. Lee RC, Feinbaum RL, Ambros V. The C. elegans heterochronic gene lin-4 encodes small RNAs with antisense complementarity to lin-14. Cell. 1993;75:843-854. doi:10.1016/0092-8674(93)90529-y

2. Elbashir SM, Harborth J, Lendeckel W, et al. Duplexes of 21-nucleotide RNAs mediate RNA interference in cultured mammalian cells. Nature. 2001;411:494-498. doi:10.1038/35078107

3. Mullard A. 2018 FDA drug approvals. Nat Rev Drug Discov. 2019;18:85-89. doi:10.1038/d41573-019-00014-x

4. Mullard A. 2019 FDA drug approvals. Nat Rev Drug Discov. 2020;19:79-84. doi:10.1038/d41573-020-00001-7

5. Li Z, Rana TM. Therapeutic targeting of microRNAs: current status and future challenges. Nat Rev Drug Discov. 2014;13:622-638. doi: $10.1038 / \mathrm{nrd} 4359$ 
6. Bandiera S, Pfeffer S, Baumert TF, Zeisel MB. miR-122-a key factor and therapeutic target in liver disease. J Hepatol. 2015;62:448-457. doi:10.1016/j.jhep.2014.10.004

7. Bertoli G, Cava C, Castiglioni I. MicroRNAs: new biomarkers for diagnosis, prognosis, therapy prediction and therapeutic tools for breast cancer. Theranostics. 2015;5:1122-1143. doi:10.7150/ thno. 11543

8. Ganju A, Khan S, Hafeez BB, et al. miRNA nanotherapeutics for cancer. Drug Discov Today. 2017;22:424-432. doi:10.1016/j. drudis.2016.10.014

9. Rupaimoole R, Slack FJ. MicroRNA therapeutics: towards a new era for the management of cancer and other diseases. Nat Rev Drug Discov. 2017;16:203-222. doi:10.1038/nrd.2016.246

10. Zarin DA, Tse T, Williams RJ, Califf RM, Ide NC. The ClinicalTrials.gov results database-update and key issues. $N$ Engl $J$ Med. 2011;364:852-860. doi:10.1056/NEJMsa1012065

11. Jing HZ, Qiu F, Chen SZ, Su L, Qu C. [Tripartite-motif protein 25 and pyruvate kinase $\mathrm{M} 2$ protein expression in non-small cell lung cancer]. Nan Fang Yi Ke Da Xue Xue Bao. 2015;35:437-441. Chinese.

12. van der Ree MH, de Vree JM, Stelma F, et al. Safety, tolerability, and antiviral effect of RG-101 in patients with chronic hepatitis C: a phase $1 \mathrm{~B}$, double-blind, randomised controlled trial. Lancet. 2017;389:709-717. doi:10.1016/S0140-6736(16)31715-9

13. Weng Y, Xiao H, Zhang J, Liang XJ, Huang Y. RNAi therapeutic and its innovative biotechnological evolution. Biotechnol $A d v$. 2019;37:801-825. doi:10.1016/j.biotechadv.2019.04.012

14. Tao JL, Luo M, Sun H, et al. Overexpression of tripartite motif containing 26 inhibits non-small cell lung cancer cell growth by suppressing PI3K/AKT signaling. Kaohsiung $J$ Med Sci. 2020;36:417-422. doi:10.1002/kjm2.12194

15. Huang HY, Lin Y-C-D, Li J, et al. miRTarBase 2020: updates to the experimentally validated microRNA-target interaction database. Nucleic Acids Res. 2020;48:D148-D154. doi:10.1093/nar/gkz896

16. Mullard A. 2015 FDA drug approvals. Nat Rev Drug Discov. 2016;15:73-76. doi:10.1038/nrd.2016.15

17. Santos R, Ursu O, Gaulton A, et al. A comprehensive map of molecular drug targets. Nat Rev Drug Discov. 2017;16:19-34. doi:10.1038/nrd.2016.230

18. Mullard A. 2016 FDA drug approvals. Nat Rev Drug Discov. 2017;16:73-76. doi:10.1038/nrd.2017.14

19. Mullard A. 2017 FDA drug approvals. Nat Rev Drug Discov. 2018;17:81-85. doi:10.1038/nrd.2018.4

20. Xie C, Mao X, Huang J, et al. KOBAS 2.0: a web server for annotation and identification of enriched pathways and diseases Nucleic Acids Res. 2011;39:W316-W322. doi:10.1093/nar/gkr483

21. Girard M, Jacquemin E, Munnich A, Lyonnet S, Henrion-Caude A. miR-122, a paradigm for the role of microRNAs in the liver J Hepatol. 2008;48:648-656. doi:10.1016/j.jhep.2008.01.019

22. Wang D, Sun X, Wei Y, et al. Nuclear miR-122 directly regulates the biogenesis of cell survival oncomiR miR-21 at the posttranscriptional level. Nucleic Acids Res. 2018;46:2012-2029. doi:10.1093/nar/ gkx1254

23. Turato C, Fornari F, Pollutri D, et al. MiR-122 targets SerpinB3 and is involved in sorafenib resistance in hepatocellular carcinoma. $J$ Clin Med. 2019;8:171. doi:10.3390/jcm8020171

24. Kanehisa M, Sato Y. KEGG Mapper for inferring cellular functions from protein sequences. Protein Sci. 2020;29:28-35. doi:10.1002/ pro. 3711

25. Cesana M, Cacchiarelli D, Legnini I, et al. A long noncoding RNA controls muscle differentiation by functioning as a competing endogenous RNA. Cell. 2011;147:358-369. doi:10.1016/j. cell.2011.09.028

26. Hansen TB, Jensen TI, Clausen BH, et al. Natural RNA circles function as efficient microRNA sponges. Nature. 2013;495:384-388. doi:10.1038/nature11993
27. Davis ME, Chen ZG, Shin DM. Nanoparticle therapeutics: an emerging treatment modality for cancer. Nat Rev Drug Discov. 2008;7:771-782. doi:10.1038/nrd2614

28. Muller RH, Keck CM. Challenges and solutions for the delivery of biotech drugs-a review of drug nanocrystal technology and lipid nanoparticles. $J$ Biotechnol. 2004;113:151-170. doi:10.1016/j. jbiotec.2004.06.007

29. Guan S, Zhang Q, Bao J, Hu R, Czech T, Tang J. Recognition sites for cancer-targeting drug delivery systems. Curr Drug Metab. 2019;20:815-834. doi:10.2174/1389200220666191003161114

30. Zhao H, Yuan X, Yu J, et al. Magnesium-stabilized multifunctional DNA nanoparticles for tumor-targeted and ph-responsive drug delivery. ACS Appl Mater Interfaces. 2018;10:15418-15427. doi:10.1021/acsami.8b01932

31. Corey DR. Chemical modification: the key to clinical application of RNA interference? J Clin Invest. 2007;117:3615-3622. doi:10.1172/ JCI33483

32. Forbes DC, Peppas NA. Oral delivery of small RNA and DNA. $J \quad$ Control Release. 2012;162:438-445. doi:10.1016/j. jconrel.2012.06.037

33. Grimm D, Streetz KL, Jopling CL, et al. Fatality in mice due to oversaturation of cellular microRNA/short hairpin RNA pathways. Nature. 2006;441:537-541. doi:10.1038/nature04791

34. Khan AA, Betel D, Miller ML, et al. Transfection of small RNAs globally perturbs gene regulation by endogenous microRNAs. Nat Biotechnol. 2009;27:549-555. doi:10.1038/nbt.1543

35. Zhang Y, Wang Z, Gemeinhart RA. Progress in microRNA delivery. J Control Release. 2013;172:962-974. doi:10.1016/j. jconrel.2013.09.015

36. Labbaye C, Spinello I, Quaranta MT, et al. A three-step pathway comprising PLZF/miR-146a/CXCR4 controls megakaryopoiesis. Nat Cell Biol. 2008;10:788-801. doi:10.1038/ncb1741

37. Pan W, Zhu S, Yuan M, et al. MicroRNA-21 and microRNA-148a contribute to DNA hypomethylation in lupus CD4 $+\mathrm{T}$ cells by directly and indirectly targeting DNA methyltransferase 1 . J Immunol. 2010;184:6773-6781. doi:10.4049/jimmunol.0904060

38. Reddy SD, Pakala SB, Ohshiro K, Rayala SK, Kumar R. MicroRNA661, a c/EBPalpha target, inhibits metastatic tumor antigen 1 and regulates its functions. Cancer Res. 2009;69:5639-5642. doi:10.1158/0008-5472.CAN-09-0898

39. Zhang J, Zhou Y, Ma L, et al. The alteration of miR-222 and its target genes in nickel-induced tumor. Biol Trace Elem Res. 2013;152:267-274. doi:10.1007/s12011-013-9619-6

40. Sun C, Li NA, Zhou BO, et al. miR-222 is upregulated in epithelial ovarian cancer and promotes cell proliferation by downregulating P27(kip1.). Oncol Lett. 2013;6:507-512. doi:10.3892/ol.2013.1393

41. Liu X, Yu J, Jiang L, et al. MicroRNA-222 regulates cell invasion by targeting matrix metalloproteinase 1 (MMP1) and manganese superoxide dismutase 2 (SOD2) in tongue squamous cell carcinoma cell lines. Cancer Genomics Proteomics. 2009;6:131-139.

42. Fornari F, Gramantieri L, Ferracin M, et al. MiR-221 controls CDKN1C/p57 and CDKN1B/p27 expression in human hepatocellular carcinoma. Oncogene. 2008;27:5651-5661. doi:10.1038/ onc. 2008.178

43. Ye Z, Hao R, Cai Y, Wang X, Huang G. Knockdown of miR-221 promotes the cisplatin-inducing apoptosis by targeting the BIM-Bax/ Bak axis in breast cancer. Tumour Biol. 2016;37:4509-4515. doi:10.1007/s13277-015-4267-4

44. Gramantieri L, Fornari F, Ferracin M, et al. MicroRNA-221 targets Bmf in hepatocellular carcinoma and correlates with tumor multifocality. Clin Cancer Res. 2009;15:5073-5081. doi:10.1158/ 1078-0432.CCR-09-0092

45. Yang T, Zhang G-F, Chen X-F, et al. MicroRNA-214 provokes cardiac hypertrophy via repression of EZH2. Biochem Biophys Res Commun. 2013;436:578-584. doi:10.1016/j.bbrc.2013.05.079 
46. Wang $\mathrm{P}$, Zou F, Zhang $\mathrm{X}$, et al. microRNA-21 negatively regulates Cdc25A and cell cycle progression in colon cancer cells. Cancer Res. 2009;69:8157-8165. doi:10.1158/0008-5472.CAN-09-1996

47. Fu YR, Liu X-J, Li X-J, et al. MicroRNA miR-21 attenuates human cytomegalovirus replication in neural cells by targeting Cdc25a. J Virol. 2015;89:1070-1082. doi:10.1128/JVI.01740-14

48. Zhang S, Wan Y, Pan T, et al. MicroRNA-21 inhibitor sensitizes human glioblastoma U251 stem cells to chemotherapeutic drug temozolomide. J Mol Neurosci. 2012;47:346-356. doi:10.1007/ s12031-012-9759-8

49. Asangani IA, Rasheed SAK, Nikolova DA, et al. MicroRNA-21 (miR-21) post-transcriptionally downregulates tumor suppressor Pdcd4 and stimulates invasion, intravasation and metastasis in colorectal cancer. Oncogene. 2008;27:2128-2136. doi:10.1038/sj. onc. 1210856

50. Hiyoshi Y, Kamohara H, Karashima R, et al. MicroRNA-21 regulates the proliferation and invasion in esophageal squamous cell carcinoma. Clin Cancer Res. 2009;15:1915-1922. doi:10.1158/ 1078-0432.CCR-08-2545

51. Li S, Fu H, Wang Y, et al. MicroRNA-101 regulates expression of the v-fos FBJ murine osteosarcoma viral oncogene homolog (FOS) oncogene in human hepatocellular carcinoma. Hepatology. 2009;49:1194-1202. doi:10.1002/hep.22757

52. Luo W, Li G, Yi Z, Nie Q, Zhang X. E2F1-miR-20a-5p/20b-5p auto-regulatory feedback loop involved in myoblast proliferation and differentiation. Sci Rep. 2016;6:27904. doi:10.1038/srep27904

53. Ryan J, Tivnan A, Fay J, et al. MicroRNA-204 increases sensitivity of neuroblastoma cells to cisplatin and is associated with a favourable clinical outcome. Br J Cancer. 2012;107:967-976. doi:10.1038/ bjc.2012.356

54. Luan W, Qian Y, Ni X, et al. miR-204-5p acts as a tumor suppressor by targeting matrix metalloproteinases-9 and B-cell lymphoma-2 in malignant melanoma. Onco Targets Ther. 2017;10:1237-1246. doi:10.2147/OTT.S128819

55. Cochrane DR, Spoelstra NS, Howe EN, Nordeen SK, Richer JK. MicroRNA-200c mitigates invasiveness and restores sensitivity to microtubule-targeting chemotherapeutic agents. Mol Cancer Ther. 2009;8:1055-1066. doi:10.1158/1535-7163.MCT-08-1046

56. Zhang QQ, Xu H, Huang M-B, et al. MicroRNA-195 plays a tumor-suppressor role in human glioblastoma cells by targeting signaling pathways involved in cellular proliferation and invasion. Neuro Oncol. 2012;14:278-287. doi:10.1093/neuonc/nor216

57. Jia LF, Wei SB, Gong K, Gan YH, Yu GY, Kim AL. Prognostic implications of micoRNA miR-195 expression in human tongue squamous cell carcinoma. PLoS One. 2013;8:e56634. doi:10.1371/ journal.pone. 0056634

58. Luo Q, Wei C, Li X, et al. MicroRNA-195-5p is a potential diagnostic and therapeutic target for breast cancer. Oncol Rep. 2014;31:1096-1102. doi:10.3892/or.2014.2971

59. Han K, Chen X, Bian N, et al. MicroRNA profiling identifies MiR-195 suppresses osteosarcoma cell metastasis by targeting CCND1. Oncotarget. 2015;6:8875-8889. doi:10.18632/oncotarget.3560

60. Ji J, Yamashita T, Budhu A, et al. Identification of microRNA-181 by genome-wide screening as a critical player in EpCAM-positive hepatic cancer stem cells. Hepatology. 2009;50:472-480. doi:10.1002/hep.22989

61. Zhang XJ, Ye H, Zeng CW, et al. Dysregulation of miR-15a and miR-214 in human pancreatic cancer. J Hematol Oncol. 2010;3:46. doi:10.1186/1756-8722-3-46

62. Pogue AI, Li YY, Cui J-G, et al. Characterization of an NF-kappaBregulated, miRNA-146a-mediated down-regulation of complement factor $\mathrm{H}(\mathrm{CFH})$ in metal-sulfate-stressed human brain cells. $J$ Inorg Biochem. 2009;103:1591-1595. doi:10.1016/j.jinorgbio.2009.05.012

63. Xu Z, Zeng X, Xu J, et al. Isorhapontigenin suppresses growth of patient-derived glioblastoma spheres through regulating miR-145/ SOX2/cyclin D1 axis. Neuro Oncol. 2016;18:830-839. doi:10.1093/ neuonc/nov298
64. Minami K, Taniguchi K, Sugito N, et al. MiR-145 negatively regulates Warburg effect by silencing KLF4 and PTBP1 in bladder cancer cells. Oncotarget. 2017;8:33064-33077. doi:10.18632/ oncotarget. 16524

65. Hu M, Xia M, Chen X, et al. MicroRNA-141 regulates Smad interacting protein 1 (SIP1) and inhibits migration and invasion of colorectal cancer cells. Dig Dis Sci. 2010;55:2365-2372. doi:10.1007/ s10620-009-1008-9

66. Liu LY, Wang W, Zhao LY, et al. Mir-126 inhibits growth of SGC-7901 cells by synergistically targeting the oncogenes PI3KR2 and Crk, and the tumor suppressor PLK2. Int $J$ Oncol. 2014;45:1257-1265. doi:10.3892/ijo.2014.2516

67. Bai S, Nasser MW, Wang B, et al. MicroRNA-122 inhibits tumorigenic properties of hepatocellular carcinoma cells and sensitizes these cells to sorafenib. J Biol Chem. 2009;284:32015-32027. doi:10.1074/ jbc.M109.016774

68. Sampath D, Calin GA, Puduvalli VK, et al. Specific activation of microRNA106b enables the p73 apoptotic response in chronic lymphocytic leukemia by targeting the ubiquitin ligase Itch for degradation. Blood. 2009;113:3744-3753. doi:10.1182/blood-200809-178707

69. Luo ZL, Luo H-J, Fang C, et al. Negative correlation of ITCH E3 ubiquitin ligase and miRNA-106b dictates metastatic progression in pancreatic cancer. Oncotarget. 2016;7:1477-1485. doi:10.18632/ oncotarget. 6395

70. Varambally S, Cao Q, Mani R-S, et al. Genomic loss of microRNA-101 leads to overexpression of histone methyltransferase EZH2 in cancer. Science. 2008;322:1695-1699. doi:10.1126/ science. 1165395

71. Alajez NM, Shi W, Hui ABY, et al. Enhancer of Zeste homolog 2 (EZH2) is overexpressed in recurrent nasopharyngeal carcinoma and is regulated by miR-26a, miR-101, and miR-98. Cell Death Dis. 2010;1:e85. doi:10.1038/cddis.2010.64

72. Chen DL, Ju H-Q, Lu Y-X, et al. Long non-coding RNA XIST regulates gastric cancer progression by acting as a molecular sponge of miR-101 to modulate EZH2 expression. J Exp Clin Cancer Res. 2016;35:142. doi:10.1186/s13046-016-0420-1

73. Liu J, Lu K-H, Liu Z-L, et al. MicroRNA-100 is a potential molecular marker of non-small cell lung cancer and functions as a tumor suppressor by targeting polo-like kinase 1. BMC Cancer. 2012;12:519. doi:10.1186/1471-2407-12-519

74. Nasser MW, Datta J, Nuovo G, et al. Down-regulation of micro-RNA-1 (miR-1) in lung cancer. Suppression of tumorigenic property of lung cancer cells and their sensitization to doxorubicin-induced apoptosis by miR-1. $J$ Biol Chem. 2008;283:33394-33405. doi:10.1074/jbc.M804788200

75. Zhu X, Wu L, Yao J, et al. MicroRNA let-7c inhibits cell proliferation and induces cell cycle arrest by targeting CDC25A in human hepatocellular carcinoma. PLoS One. 2015;10:e124266. doi:10.1371/journal.pone.0124266

76. Ye Z, Shen N, Weng Y, et al. Low miR-145 silenced by DNA methylation promotes NSCLC cell proliferation, migration and invasion by targeting mucin 1. Cancer Biol Ther. 2015;16:1071-1079. doi:10.1080/15384047.2015.1046024

77. Vilardo E, Barbato C, Ciotti M, Cogoni C, Ruberti F. MicroRNA-101 regulates amyloid precursor protein expression in hippocampal neurons. J Biol Chem. 2010;285:18344-18351. doi:10.1074/jbc. M110.112664

78. Garzon R, Liu S, Fabbri M, et al. MicroRNA-29b induces global DNA hypomethylation and tumor suppressor gene reexpression in acute myeloid leukemia by targeting directly DNMT3A and 3B and indirectly DNMT1. Blood. 2009;113:6411-6418. doi:10.1182/blood2008-07-170589

79. Zhang X, Zhu W, Zhang J, et al. MicroRNA-650 targets ING4 to promote gastric cancer tumorigenicity. Biochem Biophys Res Commun. 2010;395:275-280. doi:10.1016/j.bbrc.2010.04.005 
80. Zhang J, Zhao H, Chen J, et al. Interferon-beta-induced miR-155 inhibits osteoclast differentiation by targeting SOCS1 and MITF. FEBS Lett. 2012;586:3255-3262. doi:10.1016/j.febslet.2012.06.047

81. Lei $\mathrm{K}, \mathrm{Du} \mathrm{W}$, Lin $\mathrm{S}$, et al. 3B, a novel photosensitizer, inhibits glycolysis and inflammation via miR-155-5p and breaks the JAK/ STAT3/SOCS1 feedback loop in human breast cancer cells. Biomed Pharmacother. 2016;82:141-150. doi:10.1016/j.biopha.2016.04.049

82. Pathak S, Grillo AR, Scarpa M, et al. MiR-155 modulates the inflammatory phenotype of intestinal myofibroblasts by targeting SOCS1 in ulcerative colitis. Exp Mol Med. 2015;47:e164. doi:10.1038/ emm.2015.21

83. Ji J, Zhao L, Budhu A, et al. Let-7g targets collagen type I alpha2 and inhibits cell migration in hepatocellular carcinoma. J Hepatol. 2010;52:690-697. doi:10.1016/j.jhep.2009.12.025

84. Majid S, Dar AA, Saini S, et al. Regulation of minichromosome maintenance gene family by microRNA-1296 and genistein in prostate cancer. Cancer Res. 2010;70:2809-2818. doi:10.1158/00085472.CAN-09-4176

85. Chen J, Feilotter HE, Paré GC, et al. MicroRNA-193b represses cell proliferation and regulates cyclin D1 in melanoma. Am J Pathol. 2010;176:2520-2529. doi:10.2353/ajpath.2010.091061
86. Tie J, Pan Y, Zhao L, et al. MiR-218 inhibits invasion and metastasis of gastric cancer by targeting the Robol receptor. PLoS Genet. 2010;6:e1000879. doi:10.1371/journal.pgen.1000879

87. Doebele C, Bonauer A, Fischer A, et al. Members of the microRNA-17-92 cluster exhibit a cell-intrinsic antiangiogenic function in endothelial cells. Blood. 2010;115:4944-4950. doi:10.1182/ blood-2010-01-264812

88. Jiang L, Liu X, Kolokythas A, et al. Downregulation of the Rho GTPase signaling pathway is involved in the microRNA-138mediated inhibition of cell migration and invasion in tongue squamous cell carcinoma. Int J Cancer. 2010;127:505-512. doi:10.1002/ ijc. 25320

89. Jin Y, Chen Z, Liu X, Zhou X. Evaluating the microRNA targeting sites by luciferase reporter gene assay. Methods Mol Biol. 2013;936:117-127. doi:10.1007/978-1-62703-083-0 10

90. Konieczkowski DJ, Garraway LA. Resistance to EGFR blockade in colorectal cancer: liquid biopsies and latent subclones. Cell Res. 2013;23:13-14. doi:10.1038/cr.2012.115

\section{Publish your work in this journal}

Drug Design, Development and Therapy is an international, peerreviewed open-access journal that spans the spectrum of drug design and development through to clinical applications. Clinical outcomes, patient safety, and programs for the development and effective, safe, and sustained use of medicines are a feature of the journal, which has also been accepted for indexing on PubMed Central. The manuscript management system is completely online and includes a very quick and fair peer-review system, which is all easy to use. Visit http://www. dovepress.com/testimonials.php to read real quotes from published authors. 